\title{
Sensitivity of Fusarium graminearum causing head blight of wheat in Brazil to tebuconazole and metconazole fungicides
}

\author{
Pierri Spolti, Bruna C. de Jorge \& Emerson M. Del Ponte \\ Alegre, RS, Brazil \\ Author for correspondence: Emerson M. Del Ponte, e-mail: emerson.delponte@ufrgs.br
}

Departamento de Fitossanidade, Faculdade de Agronomia, Universidade Federal do Rio Grande do Sul, 13083-862, Porto

\begin{abstract}
Fusarium head blight (FHB) of wheat, is caused by fungal populations belonging to the Fusarium graminearum species complex. Although triazole fungicides are widely used in FHB management, information about the sensitivity of $F$. graminearum populations to such fungicides is scarce, particularly in Brazil. This work aimed at determining the sensitivity of pathogenic populations of $F$. graminearum to metconazole and tebuconazole. Fungal isolates were obtained from diseased wheat heads collected in commercial fields at the northern region of Rio Grande do Sul state, Brazil, along the 2009 and 2010 growing seasons. Fifty isolates obtained from eleven locations were grown in media amended with increasing fungicide dosages and the effective concentration reducing mycelial growth to $50 \%\left(\mathrm{EC}_{50}\right)$ was determined. The median of the $\mathrm{EC}_{50}$ values was $0.001 \mathrm{mg} / \mathrm{L}(<0.001-0.152 \mathrm{mg} / \mathrm{L})$ and $0.037 \mathrm{mg} / \mathrm{L}(<0.001-0.324)$, for tebuconazole and metconazole, respectively. Cross-resistance was detected based on significance of correlation analysis $\left(r_{s}=0.46 ; P<0.0001\right)$ between the $\log$-transformed $\mathrm{EC}_{50}$ of the two triazoles. The mean $\mathrm{EC}_{50}$ for a group of ten isolates classified as "more sensitive" differed statistically from the ten isolates representing the "less sensitive" group. Nevertheless, these groups did not differ in terms of mycelial growth on PDA in the absence of fungicides. It was concluded that pathogenic populations of $F$. graminearum are sensitive to the triazoles at various levels due to the intrinsic characteristics of the isolates or to selection pressure by the increasing fungicide use.
\end{abstract}

Keywords: Gibberella zeae, Triticum aestivum, fungicide resistance, Fusarium head blight.

Fusarium graminearum species complex (Fg complex) comprises more than a dozen lineages or phylogenetic species (Sarver et al., 2011) and is the main causal agent of Fusarium head blight (FHB) of small grain in Brazil and around the world (Goswami and Kistler, 2005; Astolfi et al., 2012). In the Americas, Fusarium graminearum sensu stricto is the dominant species of the Fg complex associated with head blight of wheat (Alvarez et al., 2011; Schmale et al., 2011; Astolfi et al., 2012). The pathogen produces deoxynivalenol (DON), a major trichothecene mycotoxin that acts as a virulence factor (Proctor et al., 1995; Goswami and Kistler, 2005; HallemAdams et al., 2011) and may accumulate in grains at levels considered unsafe for both human and animal consumption (Pieters et al., 2002).

The most effective control measures employed to reduce FHB impact are the use resistant cultivars and fungicide application during flowering stage (Hollingsworth et al., 2008; Willyerd et al., 2012). Fungicides of the demethylation inhibitors (DMIs) group, which includes triazoles, inhibit the C-14 $\alpha$-demethylation of 24methylenedihydrolanosterol, a precursor of ergosterol in fungi (Brent, 1995). Tebuconazole, metconazole and prothioconazole are among the azole fungicides with higher efficacy in suppressing FHB symptoms and reducing mycotoxin levels in mature grain (Paul et al., 2008).
Currently, triazoles are the main fungicides used in FHB control in the major wheat producing countries (Paul et al., 2008; Becher et al., 2011).

In Europe and Asia, the increasing usage of triazoles in FHB management is suspected to have led to selection of less sensitive isolates of $F$. graminearum (Klix et al., 2007; Yin et al., 2009; Becher et al., 2010). Fungal resistance to triazoles is associated with mutations in the 14- $\alpha$ demethylase (CYP51) gene and overexpression of the ATPbinding cassette transporters (Ma and Michailides, 2005; Liu et al., 2010). As discussed by Klix et al. (2007), the decline in the sensitivity to triazoles of $F$. graminearum owing to selection is not generally considered a key determinant of the relatively low fungicide efficacy against FHB under field conditions. However, it is well known from the literature that failures in disease control have been associated with the decline in sensitivity of other important pathogens such as Monilinia fructicola (Chen et al., 2012), Venturia inaequalis (Pfeufer \& Ngugi, 2012) and Mycosphaerella graminicola (Leroux et al., 2007) due to indiscriminate use of triazoles.

Commercial mixtures that include a combination of two triazoles or a single triazole have shown the highest control efficacy in uniform trials to reduce FHB and DON levels (Paul et al., 2008). When multiple triazoles are used, it may be critical to assess cross-resistance when they have 
similar mode of action (Karaoglanidis \& Thanassoulopoulos, 2003; Klix et al., 2007). Hence, the determination of the sensitivity of the pathogenic population to the most used fungicides in disease management is a first step towards developing an anti-resistant strategy (Lu et al., 2012).

In Brazil, literature data on F. graminearum sensitivity to fungicides is scarce. Spolti et al. (2012) observed a distinct sensitivity to tebuconazole when comparing phenotypic traits of two pairs of isolates belonging to the $\mathrm{Fg}$ complex, each possessing a distinct trichothecene genotype; $F$. meridionale isolates possessing a nivalenol genotype were much more sensitive than the $F$. graminearum isolates possessing a deoxynivalenol genotype. The objective of this work was to determine the sensitivity to tebuconazole and metconazole in a regional population of $F g$ complex isolates obtained from symptomatic wheat heads and to check whether fitness costs and cross-resistance were involved.

In 2009 and 2010, commercial wheat fields at 11 municipalities in the northern wheat-growing regions of Rio Grande do Sul State, Brazil, were inspected at the time of milk and soft dough stages of grain development. In each field, wheat heads exhibiting FHB symptoms were randomly collected and taken to the laboratory. Although there was no information available about the history of fungicide spray on these fields, it was assumed that triazoles fungicides had been sprayed on the areas along the years since these products are generally used regularly for managing wheat disease in this region.

In the laboratory, symptomatic spikelets were excised from the heads and incubated under moist conditions at $25 \pm 2^{\circ} \mathrm{C}$ during 48 hours. Fungal isolations were made from colonies resembling $F$. graminearum. Monosporic isolates were obtained from each individual wheat head. Isolates obtained from a single field were taken from distinct wheat heads. The isolates were identified to species using primer set $\mathrm{Fg} 16 \mathrm{~F} / \mathrm{Fg} 16 \mathrm{R}$ primer set, which is polymorphic for the $F$. graminearum species complex. Additionally, isolates were identified to trichothecene genotype - the two acetylates of deoxynivalenol (3-ADON and 15-ADON) and nivalenol (NIV) - using primers targeting portions of the Tri3 and Tri12 toxin genes. These identifications were made as described in previous studies (Scoz et al., 2009; Astolfi et al., 2012). A total of 50 isolates was identified and represented the regional $F$. graminearum complex population as defined in this study. The municipalities where the isolates were sampled and number of isolates from each municipality (n) were as follows: Carazinho $(n=8)$, Coronel Barros ( $n=3)$, Coxilha $(n=10)$, Cruz Alta $(n=2)$, Ernestina $(n=6)$, Lagoa Vermelha $(n=1)$, Não-Me-Toque $(n=5)$, Passo Fundo $(n=4)$, Santa Bárbara do Sul $(n=3)$, Tio Hugo $(n=4)$ and Victor Graeff ( $\mathrm{n}=4)$.

Fungicide sensitivity was quantified by measuring the radial growth of the cultures on PDA (potato dextrose agar) media (Becher et al., 2010; Tateishi et al., 2010) amended with increasing concentrations of tebuconazole
(Tebuconazole Nortox 200 EC, Nortox S.A.) or metconazole (Caramba 90, BASF S.A.) (0.0; 0.01;0.05; $0.1 ; 1$ and 10 $\mathrm{mg} / \mathrm{L})$. The fungicides were added to PDA media in three replicates each. After 5 days of incubation at $23^{\circ} \mathrm{C}$ in the dark, colony diameters were measured in two perpendicular directions and the original plug diameter was subtracted. Effective concentration leading to a reduction in mycelial growth was determined for each fungicide concentration relative to the check treatment (PDA not amended with the fungicides). The experiment was repeated once in time.

Effective concentration $(\mathrm{mg} / \mathrm{L})$ leading to a $50 \%$ reduction $\left(\mathrm{EC}_{50}\right)$ of mycelial growth was calculated on the basis of linear regression analysis of log-transformed fungicide efficiency and the $\log 10$ transformed fungicide concentrations (Becher et al., 2010). Bartlett test was used to assess variance homoscedasticity and the data from the two experiments were combined $(P<0.05)$ for analysis (Chen et al., 2012).

Cumulative frequency plots of the $\mathrm{EC}_{50}$ were produced and the median and mean values were calculated for each fungicide (Pfeufer \& Ngugi, 2012). The isolates were split into two groups of ten isolates. One group was composed by the isolates with the highest $\mathrm{EC}_{50}$ and represented the "less sensitive" and ten with the lowest $\mathrm{EC}_{50}$ represented the "more sensitive" phenotypes (Pereira et al., 2012). The non-parametric Wilcoxon test was used to assess the difference between the two strain groups and between the two fungicides (Shapiro-Wilk test $P<0,001$ ).

Mycelial growth in pure PDA medium, as described previously, was used to detect fitness costs associated with the decline in fungicide sensitivity. Significant difference between the two groups of ten isolates (the more and less sensitive groups) was assessed using t-test (Becher et al., 2010). Cross-resistance was evaluated by the significance of the Spearman correlation coefficient $\left(r_{s}\right)$ between the log transformed $\mathrm{EC}_{50}$ values of tebuconazole and metconazole. All analyses were run in SAS software (SAS Institute Inc., Cary, NC, USA).

The mean $\mathrm{EC}_{50}$ of the $F$. graminearum populations was $0.0136 \mathrm{mg} / \mathrm{L}$ and $0.037 \mathrm{mg} / \mathrm{L}$ for tebuconazole and metconazole, respectively. The majority of the isolates possessed a DON genotype (15-ADON) and was identified as $F$. graminearum sensu stricto. Only two isolates possessed a NIV genotype and were identified as $F$. meridionale. For the latter, they showed very low $\mathrm{EC}_{50}$ values $(0.002$ $\mathrm{mg} / \mathrm{L}$ and $<0.0001 \mathrm{mg} / \mathrm{L}$ ) and no statistical comparison in sensitivity was made between the two species due to the small number of isolates of $F$. meridionale.

Cumulative frequency plots for the distribution of the $\mathrm{EC}_{50}$ values for all isolates showed a much higher frequency towards the lower $\mathrm{EC}_{50}$ values for both fungicides (Figure 1A). The two triazoles differed significantly in their fungitoxicity based on the mean $\mathrm{EC}_{50}(P<0.001)$. For tebuconazole, $92 \%$ of the isolates showed $\mathrm{EC}_{50}$ between $0.01-0.03 \mathrm{mg} / \mathrm{L}$, with a maximum of $0.15 \mathrm{mg} / \mathrm{L}$. For metconazole, $85 \%$ of the isolates had $\mathrm{EC}_{50}$ between 0.03 - 

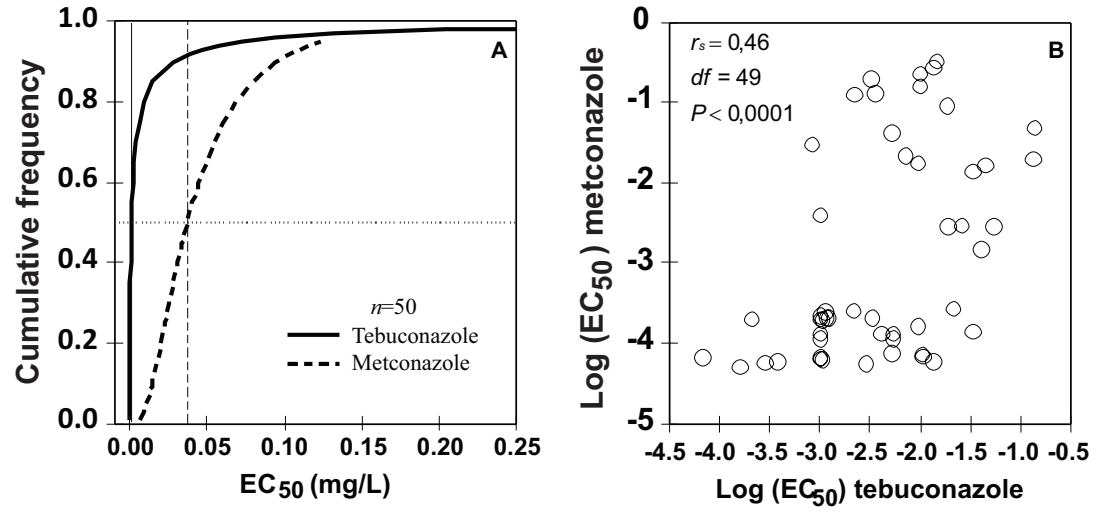

FIGURE 1 - Cumulative frequency of the effective concentration of tebuconazole and metconazole that reduces $50 \%$ of mycelial growth $\left(\mathrm{EC}_{50}\right)(\mathbf{A})$; and the relationship between the log-transformed values of $\mathrm{EC}_{50}$ of the two fungicides (B) for a series of 50 Fusarium graminearum complex isolates causing head blight of wheat originated from 11 municipalities in Rio Grande do Sul, Brazil, in the 2009 and 2010 growing seasons. Solid and dashed vertical lines in A represent the median for tebuconazole and metconazole, respectively.
$0.08 \mathrm{mg} / \mathrm{L}$, with a maximum of $0.33 \mathrm{mg} / \mathrm{L}$ (Figure 1A). A larger variability in $\mathrm{EC}_{50}$ values was observed at the upper limit, which determined higher variance in the sensitivity to metconazole ( $>\mathrm{MS}$ ) (Table 1). The median $\mathrm{EC}_{50}$ was $0.0011 \mathrm{mg} / \mathrm{L}$ and $0.0373 \mathrm{mg} / \mathrm{mL}$ for tebuconazole and metconazole, respectively, which translates into a resistance factor of 33 between these triazoles. Nevertheless, crossresistance between these two triazoles was inferred based on the significance of the correlation analysis $\left(r_{s}=0.46, P\right.$ $<0.0001$ ) (Figure 1B).

The two groups of isolates classified as more or less sensitive differed significantly $(P<0.001)$ for both fungicides. The mean $\mathrm{EC}_{50}$ in the "more sensitive" group was $0.001 \mathrm{mg} / \mathrm{L}( \pm 0.0003)$ and $0.002 \mathrm{mg} / \mathrm{L}( \pm 0.0001)$ for tebuconazole and metconazole, respectively. The largest difference between the groups was observed for metconazole (resistance factor of 83). No difference in mycelial growth rate was observed between these groups, in the absence of fungicides (Table 2).

Although we could not to compare sensitivity at the species level because of the low number of isolates belonging to F. meridionale, the two isolates belonging to that species which possessed the NIV genotype, showed the lowest $\mathrm{EC}_{50}$ values. This corroborates with our previous findings for these genotypes (Spolti et al., 2012) and suggests that the dominant species in southern Brazil - F. graminearum (possessing a 15-ADON genotype) is relatively less sensitive to triazole than other species of the complex possessing a NIV genotype (Del Ponte, unpublished). Since our study was limited to two years and a relatively small sample, it will be instructive to further assess fungicide sensitivity in a larger set of isolates representing multiple species and toxigenic genotypes belonging to the complex.

The $F$. graminearum population, investigated here was less sensitive to metconazole than tebuconazole. Contrastingly, Klix et al. (2007), assessed fungicide sensitivity of $F$. graminearum isolates, based on the ascosporic germination rate, and observed a larger decline in sensitivity over time (1987 to 2004) for tebuconazole, followed by metconazole and prothioconazole. In China, Yin et al., (2009) assessed sensitivity of 40 F. graminearum isolates to tebuconazole and found a $\mathrm{EC}_{50}$ mean of 0.248 $\mathrm{mg} / \mathrm{L}(0.021-1.152 \mathrm{mg} / \mathrm{L})$, which is much higher than those found in our study to both fungicides tested. However, in Japan, Tateishi et al. (2010) studied 101 isolates representing $F$. graminearum and $F$. asiaticum populations and found that $80 \%$ of isolates showed $\mathrm{EC}_{50}$ towards metconazole of less than $0.1 \mathrm{mg} / \mathrm{L}$, a level of sensitivity more similar to that found in the present study.

The sensitivity determined in this study constitutes a critical step for monitoring temporal and spatial changes in $\mathrm{EC}_{50}$ and identification of risk factors related to management practices leading to decline in sensitivity (Chen et al., 2012). The cross-resistance detected in our study suggests similarities in the mode of action between tebuconazole and metconazole (Karaoglanidis \& Thanassoulopoulos, 2003). Cross- resistance may have implications in chemical control and the management strategy to avoid or minimize the risk of fungicide resistance in the population (Becher et al., 2011). In the United States, the highest FHB control efficacy was achieved with a commercial mixture of prothioconazole and tebuconazole, which may be due to a synergistic effect (Liu et al., 2011). Up to now, there are not a strong evidence that regular applications of single or mixed applications of triazoles is selecting less sensitive isolates more efficiently because of cross-resistance.

We observed that the more sensitive and less sensitive isolates did not differ in mycelial growth rate. This agrees with results of Becher et al. (2010) who did not observe changes in both mycelial growth and sporulation between resistant (induced by successive cultures on media amended with $10 \mathrm{mg} / \mathrm{L}$ of tebuconazole) and the respective wild isolate. These results are supported by the recent knowledge that sensitivity to triazoles is under the control of three paralogous genes (cyp51A, cyp51B e cyp51C), which are not related to mycelial growth (Liu et al., 2011).

In conclusion, $F$. graminearum complex isolates associated with FHB in Brazil are sensitive to triazoles at various levels due to the intrinsic characteristics of the isolates or to selection pressure by the increasing use of triazoles, especially metconazole, which is currently used solely or in commercial mixtures with strobilurin targeting multiple diseases of wheat in southern Brazil. 
TABLE 1 - Effective concentration of triazol fungicides that reduces $50 \%$ of mycelial growth (EC ${ }_{50}$ ) for a series of fifty Fusarium graminearum complex isolates associated with Fusarium head blight symptoms in wheat crops from eleven municipalities in northern region of the state of Rio Grande do Sul state, Brazil, in the 2009 and 2010 growing seasons

\begin{tabular}{|c|c|c|c|c|c|c|}
\hline \multirow[t]{2}{*}{ Fungicide } & \multirow[t]{2}{*}{$\mathrm{EC}_{50}(\mathrm{mg} / \mathrm{L})^{\mathrm{x}}$} & \multirow[t]{2}{*}{ Standard error } & \multirow[t]{2}{*}{ I.C $95 \%{ }^{y}$} & \multicolumn{2}{|c|}{ Limit } & \multirow[t]{2}{*}{ Sum of squares } \\
\hline & & & & Lower & Upper & \\
\hline Tebuconazole & $0.013 \mathrm{a}$ & 0.003 & 0.007 & $<0.001$ & 0.152 & 0.036 \\
\hline Metconazole & $0.036 \mathrm{~b}$ & 0.011 & 0.022 & $<0.001$ & 0.324 & 0.353 \\
\hline
\end{tabular}

${ }^{x}$ Means followed by different letters in the column are significantly different according to Wilcoxon test $(\mathrm{P}<0,05)$.

y $95 \%$ confidence interval for $\mathrm{EC}_{50}$.

TABLE 2 - Effective concentration of triazol fungicides that reduces $50 \%$ of mycelial growth $\left(\mathrm{EC}_{50}\right)$ and the radial mycelial growth rate in the absence of fungicide in PDA media for selected isolates of $F$. graminearum grouped by sensitivity levels and that were associated with Fusarium head blight symptoms in wheat crops from 11 municipalities in the northern region of the state of Rio Grande do Sul state, Brazil, 2009 and 2010 growing seasons

\begin{tabular}{|c|c|c|c|}
\hline \multirow[t]{2}{*}{ Sensitivity group ${ }^{w}$} & \multicolumn{2}{|c|}{$\mathrm{EC}_{50}(\mathrm{mg} / \mathrm{L})^{\mathrm{x}}$} & \multirow[t]{2}{*}{ Mycelial growth $(\mathrm{mm} / \text { day })^{z}$} \\
\hline & Tebuconazole & Metconazole & \\
\hline More sensitive $(n=10)$ & $0.001 \mathrm{a}( \pm 0.0003)$ & $0.002 \mathrm{a}( \pm 0.0001)$ & $1.20^{\mathrm{ns}}$ \\
\hline Less sensitive $(\mathrm{n}=10)$ & $0.053 \mathrm{~b}( \pm 0.0395)$ & $0.166 \mathrm{~b}( \pm 0.0894)$ & 1.10 \\
\hline Resistance factor ${ }^{\mathrm{y}}$ & 53 & 83 & \\
\hline
\end{tabular}

${ }^{\mathrm{w}}$ Each group was composed by ten highest (less sensitive) and the ten lowest (more sensitive) $\mathrm{EC}_{50}$ values for the 50 isolates.

${ }^{x}$ Mean (standard error) of $\mathrm{EC}_{50}$ values followed by different letters in the same column differ significantly according Wilcoxon test $(P<0.05)$.

${ }^{y}$ Calculated by dividing $\mathrm{EC}_{50}$ of the less sensitive by the respectively more sensitive group.

${ }^{z}$ Daily mycelial growth rate from colonies in PDA without fungicides amended. Mean differences by t-test $(P>0.05)$.

\section{ACKNOWLEDGEMENTS}

Authors are grateful to Sami J. Michereff (Universidade Federal Rural de Pernambuco) for critically reviewing a preliminary version of the manuscript and to BASF Chemical Company for providing the fungicides tested in this study. First and third authors are thankful to the Conselho Nacional do Desenvolvimento Científico e Tecnológico - CNPq for providing the authors with a research scholarship and research fellowship, respectively.

\section{REFERENCES}

Alvarez CL, Somma S, Proctor RH, Stea G, Mulè G, Logrieco AF, PintoVF, Moretti A (2011) Genetic diversity in Fusarium graminearum from a major wheat-producing region of Argentina. Toxins 3:1294-1309.

Astolfi P, Reynoso MM, Ramirez ML, Chulze SN, Alves TCA, Tessmann DJ, Del Ponte EM (2012) Genetic population structure and trichothecene genotypes of Fusarium graminearum isolated from wheat in southern Brazil. Plant Pathology 61:289-295.

Becher R, Hettwer U, Karlovsky P, Deising HB, Wirsel SGR (2010) Adaptation of Fusarium graminearum to tebuconazole yielded descendants diverging for levels of fitness, fungicide resistance, virulence, and mycotoxin production. Phytopathology 100:444-453.

Becher R, Weihmann F, Deising HB, Wirsel SGR (2011) Development of a novel multiplex DNA microarray for Fusarium graminearum and analysis of azole fungicide responses. BMC Genomics 12:52.
Brent KJ (1995) Fungicide resistance in crop pathogens, how can it be managed? Brussels Belgium. Global Crop Protection Federation.

Chen FP, Fan JR, Zhou T, Liu XL, Liu JL, Schnabel G (2012) Baseline sensitivity of Monilinia fructicola from China to the DMI fungicide SYP-Z048 and analysis of DMI-resistant mutants. Plant Disease 96:416-422.

Goswami RS, Kistler HC (2005) Pathogenicity and in planta mycotoxin accumulation among members of the Fusarium graminearum species complex on wheat and rice. Phytopathology 95:1397-1404.

Hallen-Adams HE, Wenner N, Kuldau GA, Trail F (2011) Deoxynivalenol biosynthesis-related gene expression during wheat kernel colonization by Fusarium graminearum. Phytopathology 101:1091-1096.

Hollingsworth CR, Motteberg CD, Wiersma JV, Atkinson LM (2008) Agronomic and economic responses of spring wheat to management of Fusarium head blight. Plant Disease 92:13391348.

Karaoglanidis GS, Thanassoulopoulos CC (2003) Cross-resistance patterns among sterol biosynthesis inhibiting fungicides (SBIs) in Cercospora beticola. European Journal of Plant Pathology 109:929-934.

Klix MB, Verreet J-A, Beyer M (2007) Comparison of the declining triazole sensitivity of Gibberella zeae and increased sensitivity achieved by advances in triazole fungicide development. Crop Protection 26:683-690.

Leroux P, Albertini C, Gautier A, Gredt M, Walker AS (2007) Mutations in the CYP51 gene correlated with changes in sensitivity 
to sterol 14 alpha-demethylation inhibitors in field isolates of Mycosphaerella graminicola. Pest Management Science 63:688698.

Liu X, Jiang J, Shao J, Yin Y, Ma Z (2010) Gene transcription profiling of Fusarium graminearum treated with an azole fungicide tebuconazole. Applied Microbiology and Biotechnology 85:11051114.

Liu X, Yu F, Schnabel G, Wu J, Wang Z, Ma Z (2011) Paralogous cyp51 genes in Fusarium graminearum mediate differential sensitivity to sterol demethylation inhibitors. Fungal Genetics and Biology 48:113-123.

Lu XH, Davis RM, Livingston S, Nunez J, Hao JJ (2012) Fungicide sensitivity of Pythium spp. associated with cavity spot of carrot in California and Michigan. Plant Disease 96:384-388.

Ma Z, Michailides TJ (2005) Advances in understanding molecular mechanisms of fungicide resistance and molecular detection of resistant genotypes in phytopathogenic fungi. Crop Protection 24:853-863.

Paul PA, Lipps PE, Hershman DE, McMullen MP, Draper MA, Madden LV (2008) Efficacy of triazole-based fungicides for Fusarium head blight and deoxynivalenol control in wheat: A multivariate meta-analysis. Phytopathology 98:999-1011.

Pereira AVS, Martins RB, Michereff SJ, Silva MB, Câmara MPS (2012) Sensitivity of Lasiodiplodia theobromae from Brazilian papaya orchards to MBC and DMI fungicides. European Journal of Plant Pathology 132:489-498.

Pfeufer EE, Ngugi HK (2012) Orchard factors associated with resistance and cross resistance to sterol demethylation inhibitor fungicides in populations of Venturia inaequalis from Pennsylvania. Phytopathology 102:272-282.

Pieters MN, Freijer J, Baars BJ, Fiolet DC, van Klaveren J, Slob W (2002) Risk assessment of deoxynivalenol in food: concentration limits, exposure and effects. Advances in Experimental Medicine and Biology. 504:235-48.

Proctor RH, Hohn TM, McCormick SP (1995) Reduced virulence of Gibberella zeae caused by disruption of a trichothecene toxin biosynthetic gene. Molecular Plant-Microbe Interactions. 8:593601.

Sarver BA, Ward TJ, Gale LR, Broz K, Kistler HC, Aoki T, Nicholson P, Carter J, O'Donnell K (2011) Novel Fusarium head blight pathogens from Nepal and Louisiana revealed by multilocus genealogical concordance. Fungal Genetics and Biology 48:10961107.

Schmale DG, Wood-Jones AK, Cowger C, Bergstrom GC, Arellano C (2011) Trichothecene genotypes of Gibberella zeae from winter wheat fields in the eastern USA. Plant Pathology 60:909-917.

Scoz LB, Astolfi P, Reartes DS, Schmale DG III, Moraes MG, Del Ponte EM (2009) Trichothecene mycotoxin genotypes of Fusarium graminearum sensu stricto and Fusarium meridionale in wheat from Southern Brazil. Plant Pathology 58:344-351.

Spolti P, Barros NC, Gomes LB, Santos J, Del Ponte EM (2012) Phenotypic and pathogenic traits of two species of the Fusarium graminearum complex possessing either 15-ADON or NIV genotype. European Journal Plant Pathology 133:621-629.

Tateishi H, Miyake T, Mori M, Kimura R, Sakuma Y, Saishoji T (2010) Sensitivity of Japanese Fusarium graminearum species complex isolates to metconazole. Journal of Pesticide Science 35:419-430.

Willyerd KT, Li C, Madden LV et al. (2012) Efficacy and stability of integrating fungicide and cultivar resistance to manage Fusarium head blight and deoxynivalenol in wheat. Plant Disease 96:957-967.

Yin Y, Liu X, Li B, Ma Z (2009) Characterization of sterol demethylation inhibitor-resistant isolates of Fusarium asiaticum and $F$. graminearum collected from wheat in China. Phytopathology 99:487-497.

TPP 585 - Received 13 April 2012 - Accepted 26 August 2012 Section Editor: Marciel J. Stadnik 